\title{
A relationship between endoscopic findings and diabetic regulation, and complications in patients with diabetes mellitus
}

Sevki Konur

Department of Internal Medicine, Van Education and Research Hospital, Van, Turkey

Submitted: 21 July 2020

Accepted: 29 July 2020

Arch Med Sci Civil Dis 2020; 5: e53-e57

DOI: https://doi.org/10.5114/amscd.2020.100979

Copyright $\odot 2020$ Termedia \& Banach

\begin{abstract}
Introduction: Diabetes mellitus (DM) is the most common endocrine disease. Increasing with a rapid acceleration, DM affects the society both financially and socially with its possible complications. Dyspeptic complaints occur in approximately $40 \%$ of DM patients. Dyspepsia in DM is a difficult condition to treat and requires patients' frequent hospital visits. We aimed to examine a relationship between diabetic regulation and diabetic complications as well as endoscopic findings in patients with DM and dyspeptic complaints.

Material and methods: Patients with a DM diagnosis from internal diseases outpatient clinic of our hospital who were followed-up between January 2019 and June 2020, and who underwent endoscopy for the upper gastrointestinal system were included. Diagnosis of DM was made according to the American Diabetes Association (ADA) criteria. Diabetic complications were questioned. A relationship between endoscopic and histopathological findings, glycated hemoglobin $\left(\mathrm{HbA}_{1 \mathrm{c}}\right)$ level, and complications was investigated. Results: A total of 105 patients, 61 (58\%) females, were included into the study. In a comparison between the groups, there was no statistically significant difference between glycemic regulation and endoscopic findings and the presence of HP. Comparing diabetic complications, no significant difference was observed in patients with complications from the endoscopic findings, except for pangastritis. The presence of HP was similar in both groups. Conclusions: It can be said that endoscopic findings and presence of HP are not closely related to glycemic control and complications in diabetic patients. However, these results should be supported by larger, multi-center, prospective studies.
\end{abstract}

Key words: diabetes mellitus, dyspepsia, endoscopy.

\section{Introduction}

Diabetes mellitus (DM) is one of the most common health problems. In 2000, there were 150 million (4.6\%) DM patients; today, the number increased to 463 million (9.3\%) and is expected to reach 578 million (10.2\%) in 2030 and 700 million (10.9\%) in 2045 [1-3]. Increasing with such a fast acceleration, DM and its treatment create a serious financial burden. In addition, DM affects the society both financially and socially with its possible complications. The identification and management process of diabetic complications is quite exhausting $[4,5]$. The importance

\author{
Corresponding author: \\ Sevki Konur \\ Department \\ of Internal Medicine \\ Van Education and \\ Research Hospital \\ Van, Turkey \\ E-mail: sevkikonur@gmail. \\ com
}


of this process could be better understood when the management of micro and/ or macrovascular complications in DM patients fails, with the loss of workforce and organ damage that may occur $[6,7]$.

Dyspeptic complaints are noted in approximately $40 \%$ of DM patients $[8,9]$. Although diabetic gastroparesis is mostly known without gastric outlet obstruction, delayed gastric emptying time and upper gastrointestinal system (GIS) complaints, reflux, constipation, and inflammatory pain in epigastric region are frequently observed in DM patients. In general, it is known that dyspeptic complaints in DM patients seriously impair their quality of life, are slow, difficult, and sometimes unresponsive to treatment, with upper GIS endoscopy at frequent intervals performed due to complaints $[8,9]$.

In our study, we aimed to examine the relationship between diabetic regulation and diabetic complications and endoscopic findings in patients with DM diagnosis and dyspeptic complaints who underwent upper GIS endoscopy.

\section{Material and methods}

\section{Study design}

In total, 105 patients with a DM diagnosis and dyspeptic complaints, reported in internal diseases outpatient clinic of our hospital who were followed-up between January 2019 and June 2020, and who underwent endoscopy for the upper gastrointestinal system were included into this retrospective study. Pregnant women, patients with organ transplantation (liver, kidney, bone marrow), and patients with chronic disease, except diabetes related complications (renal, vascular, cardiac, orthopedic, eye) were excluded. Demographic features (age, gender), previous treatments, smoking, alcohol use, and presence of diabetic complications (retinopathy, nephropathy, neuropathy, cardiovascular diseases, cerebrovascular events, extremity pathology, such as peripheral vascular diseases and limb amputation) were documented.

\section{Clinical and laboratory measurements}

The diagnosis of DM was made according to ADA criteria. Patients with fasting plasma glucose above $126 \mathrm{mg} / \mathrm{dl}$, with randomly examined blood glucose above $200 \mathrm{mg} / \mathrm{dl}$ according to DM diagnostic criteria, with an oral glucose tolerance test (OGTT) of $2 \mathrm{~h}$ above blood glucose 200 and glycated hemoglobin $\left(\mathrm{HbA}_{1 \mathrm{c}}\right)$ value above $6.5 \%$ were accepted as DM [10]. Those with $\mathrm{HbA}_{1 \mathrm{c}}<7 \%$ were considered as good glycemic control, and those with $\mathrm{HbA}_{1 c}>7 \%$ as poor glycemic control. Systolic and diastolic blood pressures were measured using an automatic sphygmomanometer, with a suitable cuff size on the right arm after a 10-minute rest period. Those with systolic/ diastolic blood pressure $\geq 140 / 90 \mathrm{~mm} \mathrm{Hg}$ or those using antihypertensive drugs were considered as hypertensive patients [10].

\section{Diabetic complications}

All patients were examined by an ophthalmologist, and the presence of retinopathy was investigated. For nephropathy, urinalysis, protein in 24 hour urine, and creatinine clearance were analyzed. Glomerular filtration rate was calculated, and urinary ultrasonography was performed. Patients were requested to report complaints such as burning, tingling, pain, and stinging in the extremities, and the presence of neuropathy was evaluated. In patients with joint pain, the presence of arthropathy was investigated by direct joint radiography and magnetic resonance. With the examination and electrocardiogram performed by the cardiologist and cardiovascular surgeon, the presence of cardiovascular disease was examined by performing echocardiography, coronary angiography, and vascular ultrasonography. The presence of cerebrovascular disease was documented by clinical interrogation and neurological examination.

\section{Endoscopic evaluation}

Endoscopic findings and histopathological data of the patients were documented. Endoscopies were performed with Fujinon EG530WR endoscopy device in an endoscopy unit of our hospital. Oral and written consents were obtained before the endoscopy. All patients fasted for $6 \mathrm{~h}$ before the procedure, and after local pharyngeal xylocaine anesthesia, the endoscopy was performed. Duodenum was examined in detail during the procedure, and biopsies were taken for Helicobacter pylori infection from the stomach. In DM patients, the relationship between endoscopic and histopathological findings, $\mathrm{HbA}_{1 c}$ level, and complications were analyzed.

\section{Histopathological evaluation}

During the endoscopy, punch biopsy was taken from the stomach using a biopsy forceps, and the biopsy materials were sent to a pathology laboratory in $10 \%$ formaldehyde. Tissue samples embedded in paraffin were cut into 5-micron thickness, stained with giemsa, and evaluated under a light microscope. Samples without tissue adequacy were excluded from the evaluation. The biopsy materials taken were assessed for HP presence by three experienced pathologists without clinical information.

\section{Statistical analysis}

The results of our study were analyzed with Statistical Package for the Social Sciences 19.0 
(SPSS Armonk, NY: IBM Corp., USA). Data that received continuous values were given as mean ( \pm standard deviation), and categorical data as frequency and percentage ( $n, \%)$. Data were tested for compliance with the normal distribution using the Kolmogorov-Smirnov test, histogram, and \pm standard deviation. Parametric data of the groups were compared using Student's $t$ test, and $\chi^{2}$ test was used for categorical data. $P<0.05$ was considered statistically significant.

\section{Results}

A total of 105 patients, 61 (58\%) females and $44(42 \%)$ males were included in the study. In $\mathrm{HbA}_{1 \mathrm{c}}$ values analysis, there were 25 patients with $\mathrm{HbA}_{1 \mathrm{c}}$ value $\leq 7$ and 80 patients with $\mathrm{HbA}_{1 \mathrm{c}}$ value $>7$. In the demographic comparison between the two groups based on $\mathrm{HbA}_{1 \mathrm{c}}$ values, no significant difference was noted in terms of age and gender $(p>0.05)$. In the endoscopic findings' examination, no significant difference between the groups $(p>0.05)$ was observed. Moreover, there was no significant difference between the groups regarding HP examination $(p>0.05)$ (Table I).

When the patients were examined for the presence of complications, 42 (40\%) patients had diabetic complications and 63 (60\%) patients had no diabetic complications. Comparing the groups, it was observed that the frequency of complications improved with increasing age, and the difference was found statistically significant $(p=0.014)$.
There was no significant difference between the groups regarding gender $(p=0.872)$. In endoscopic findings between the two groups, it was observed that pangastritis was observed in patients with complications at a higher rate, with a statistically significant difference between the groups $(p=0.035)$. There was no significant difference in terms of other endoscopic findings. There was no statistically significant difference in the comparison of HP presence between the groups ( $p=$ 0.421) (Table II).

\section{Discussion}

Diabetes mellitus is a chronic metabolic and the most common endocrine disease in the world, which requires constant medical care, and the organism of DM patient cannot benefit enough from carbohydrates, fats, and proteins intake due to insulin deficiency or defects in insulin effect. DM's frequency is increasing gradually $[10,11]$. In our country, as per the first study on the prevalence of diabetes, conducted in 1998-1999 as Turkey Diabetes, Hypertension, Obesity and Endocrinology Diseases Prevalence (TURDEP) study, DM was determined as 7.7\%, while in 2010, TURDEP || study revealed DM to reach $13.7 \%[12,13]$.

Treatment of diabetes and its complications is a serious financial burden. Approximately, 600 billion dollars were spent in the world in 2015 for the treatment of diabetes and its complications. Today, this expenditure is over 1 trillion dollars $[6,7]$.

Table I. Comparison of endoscopic findings, demographic characteristics, and HP presence in $\mathrm{HbA}_{1 \mathrm{c}}$ levels

\begin{tabular}{|c|c|c|c|}
\hline Parameter & $\mathrm{HbA}_{1 \mathrm{c}} \leq 7(n=25)$ & $\mathrm{HbA}_{1 \mathrm{c}}>7(n=80)$ & $P$-value \\
\hline Age [year] & $54.5 \pm 13.1$ & $58.9 \pm 13.5$ & 0.158 \\
\hline Sex (female, \%) & $14(56)$ & $47(58.8)$ & 0.808 \\
\hline \multicolumn{4}{|l|}{ Endoscopic findings, $n(\%)$ : } \\
\hline Antral gastritis & $10(40)$ & $23(28.8)$ & 0.290 \\
\hline Pangastritis & $14(56)$ & $57(71.3)$ & 0.155 \\
\hline Esophagitis & $6(24)$ & $27(35)$ & 0.305 \\
\hline Gastric ulcer & $3(12)$ & $6(7.5)$ & 0.483 \\
\hline Duodenal ulcer & $1(4)$ & $5(6.3)$ & 0.672 \\
\hline Bulbitis & $0(0)$ & $2(2.5)$ & 0.475 \\
\hline Hiatal hernia & $0(0)$ & $3(3.8)$ & 0.326 \\
\hline LES disfunction & $0(0)$ & $2(2.5)$ & 0.475 \\
\hline Alkaline reflux gastritis & $0(0)$ & $2(2.5)$ & 0.475 \\
\hline Barret metaplasia & $0(0)$ & $0(0)$ & - \\
\hline Atrophic gastritis & $1(4)$ & $1(1.3)$ & 0.380 \\
\hline HP, $n(\%)$ & $13(52.0)$ & $47(58.8)$ & 0.552 \\
\hline
\end{tabular}


Table II. Comparison of endoscopic findings, demographic features, and HP presence according to the occurrence of diabetic complications

\begin{tabular}{|c|c|c|c|}
\hline Parameter & $\begin{array}{l}\text { Diabetes mellitus with } \\
\text { complications }(n=42)\end{array}$ & $\begin{array}{l}\text { Diabetes mellitus without } \\
\text { complications }(n=63)\end{array}$ & $P$-value \\
\hline Age [year] & $61.7 \pm 12.9$ & $55.2 \pm 13.3$ & 0.014 \\
\hline Sex (female, \%) & $24(57.1)$ & $37(58.7)$ & 0.872 \\
\hline \multicolumn{4}{|l|}{ Endoscopic findings, $n(\%)$ : } \\
\hline Antral gastritis & $9(21.4)$ & $24(38.1)$ & 0.072 \\
\hline Pangastritis & $33(78.6)$ & $37(58.7)$ & 0.035 \\
\hline Esophagitis & $15(35.7)$ & $19(30.2)$ & 0.551 \\
\hline Gastric ulcer & $4(9.5)$ & $5(7.9)$ & 0.776 \\
\hline Duodenal ulcer & $3(7.1)$ & $3(4.8)$ & 0.607 \\
\hline Bulbitis & $1(2.4)$ & $1(1.6)$ & 0.771 \\
\hline Hiatal hernia & $2(4.8)$ & $1(1.6)$ & 0.339 \\
\hline LES disfunction & $2(4.8)$ & $0(0)$ & 0.080 \\
\hline Alkaline reflux gastritis & $1(2.4)$ & $1(1.6)$ & 0.771 \\
\hline Barret metaplasia & $0(0)$ & $0(0)$ & - \\
\hline Atrophic gastritis & $0(0)$ & $2(3.2)$ & 0.244 \\
\hline HP, $n(\%)$ & $26(61.9)$ & $34(54)$ & 0.421 \\
\hline
\end{tabular}

$H b A_{1 c}$ - hemoglobin $A_{1 c}, H P-$ Helicobacter pylori.

The vast majority of the expenditures were made for the treatment of developed complications. As a result of modern treatments that develop and continue to grow rapidly in DM, an increase in the frequency of complications, which imposes serious burdens on health and economy is also observed $[6,7]$. Complications include an increase in $\mathrm{HbA}_{1 c}$ level. Therefore, glycemic control is very important in DM patients. Given the linear relationship between microvascular and macrovascular complications, and $\mathrm{HbA}_{1 \mathrm{c}}$ level, the American Diabetes Association (ADA) proposes to keep the target $\mathrm{HbA}_{1 c}$ level below 7\% [14-18]. Similar studies have demonstrated a relationship between dyspeptic complaints and diabetic regulation, with dyspeptic complaints being higher in DM patients with poor glycemic control $[19,20]$. In the study conducted by Oner et al., who investigated frequency of dyspeptic complaints among diabetic and non-diabetic patients, it was reported that dyspeptic complaints were significantly higher in DM patients [19].

Although dyspeptic complaints are frequent in DM patients, it is not clear whether there is any difference between non-diabetic patients in terms of endoscopic findings, with conflicting results reported [19-22]. In a comparison of endoscopic findings between two groups of patients, Oner et al. showed that the frequency of gastric ulcers was higher in DM patients, but there was no significant difference in terms of other endoscopic findings [19]. Koch et al. found no correlation between glycemic control and dyspeptic complaints and endoscopic findings [9]. Faria et al. examined the presence of HP with glycemic control and endoscopic findings in patients diagnosed with type $1 \mathrm{DM}$, and stated that diabetic patients had dyspeptic complaints at a higher rate compared to non-diabetic patients; however, there was no significant difference between the groups in terms of endoscopic findings and HP presence [20]. Similarly, in our study, no significant difference was observed between the groups in terms of HP.

In the study conducted in Taiwan, in which 7,048 non-diabetic patients and 722 diabetic patients were evaluated, endoscopic pathological findings were significantly higher in diabetic patients [21]. In a study from Greece, no significant difference was found between diabetic and non-diabetic patients in terms of HP presence. Although, there were differences in endoscopic findings between the groups, it was not statistically significant [22]. On the other hand, Vasihnav et al. found that the presence of pangastritis and bulbite was higher in patients with DM, compared to non-diabetic patients, and the presence of HP was higher [23]. In our study, there was no significant difference between endoscopic findings in comparison with $\mathrm{HbA}_{1 \mathrm{c}}$ levels in patients with 
diabetes. The presence of pangastritis was higher in patients with diabetic complications, and was considered statistically significant. However, there was no difference in terms of other endoscopic findings. In addition, there was no significant difference between the groups regarding HP.

Our study has its strengths and limitations. Small number of patients and retrospective design are the limitations of our study. Endoscopic and histopathological examination of all patients included in the study, documentation of all complications, and the comparison with endoscopic and histological data are the strengths of our study.

In conclusion, in the present study, it was demonstrated that the presence of pangastritis is significantly higher in DM patients who developed complications. Moreover, endoscopic findings and the presence of HP are not closely related to glycemic control and complications in patients with DM. However, this information should be validated by larger, multi-center, prospective studies.

\section{Conflict of interest}

The authors declare no conflict of interest.

\section{References}

1. Kayar Y, Ilhan A, Kayar NB, et al. Relationship between the poor glycemic control and risk factors, life style and complications. Biomed Res 2017; 28: 23-5.

2. Guariguata L, Whiting DR, Hambleton I, Beagley J, Linnenkamp U, Shaw JE. Global estimates of diabetes prevalence for 2013 and projections for 2035. Diabetes Res Clin Pract 2014; 103: 137-49.

3. Kayar Y, Pamukcu O, Eroglu H, et al. Relationship between Helicobacter pylori infections in diabetic patients and inflammations, metabolic syndrome, and complications. Int J Chronic Dis 2015; 2015: 290128.

4. Kayar Y, Agin M. The relationship between demographic and anthropometric characteristics and diabetic complications and number of hospitalizations in hospitalized diabetic patients. Arch Med Sci Civil Dis 2019; 4: 7-15.

5. Ma CC, Duan CC, Huang RC, Tang HQ. Association of circulating cystatin $\mathrm{C}$ levels with type 2 diabetes mellitus: a systematic review and meta-analysis. Arch Med Sci 2020; 16: 648-56.

6. Menzin J, Langley-Hawthor C, Friedman M, Boulanger L, Cavanaugh R. Potential short-term economic benefits of improved glycemic control: a managed care perspective. Diabetes Care 2001; 24: 51-5.

7. Menzin J, Korn JR, Cohen J, et al. Relationship between glycemic control and diabetes-related hospital costs in patients with type 1 or type 2 diabetes mellitus. J Manag Care Pharm 2010; 16: 264-75.

8. Bharucha AE, Kudva YC, Prichard DO. Diabetic gastroparesis. Endocr Rev 2019; 40: 1318-52.

9. Koch CA, Uwaifo GI. Are gastrointestinal symptoms related to diabetes mellitus and glycemic control? Eur J Gastroenterol Hepatol 2008; 20: 822-5.

10. American Diabetes Association. Standards of Medical Care in Diabetes. Diabetes Care 2015; 38: 8-67.

11. Satman I, Imamoğlu S, Yılmaz C, Akalın S ve Diabetes Mellitus Çalışma ve Eğitim Grubu. TEMD Diabetes
Mellitus ve Komplikasyonlarının Tanı, Tedavi ve İzlem Kılavuzu, 5. Baskı. Bayt Matbaacılık, Ankara 2011.

12. The TURDEP Group. Population-Based Study of Diabetes and Risk Characteristics in Turkey. Diabetes Care 2002; 25: 1551-6.

13. The TURDEP Group. Population-Based Study of Diabetes and Risk Characteristics in Turkey, Istanbul, 2010.

14. Zhaolan L, Chaowei F, Weibing W, Biao X. Prevalence of chronic complications of type 2 diabetes mellitus in outpatients - a cross-sectional hospital based survey in urban China. Health and Quality of Life Outcomes 2010; 8: 62.

15. Rhee SY, Chon S, Kwon MK, et al. Prevalence of chronic complications in Korean patients with type 2 diabetes mellitus based on the Korean National Diabetes Program. Diabetes Metabol J 2011; 35: 504-12.

16. Standards of Medical Care in diabetes - 2020. Diabetes Care 2020; 43 (Suppl. 1): 1-2.

17. American Diabetes Association Professional Practice Committee. American Diabetes Association clinical practice recommendations. Diabetes Care January 2013; 36 (Suppl 1): 1-110.

18. International Expert Committee. International Expert Committee report on the role of the $\mathrm{A} 1 \mathrm{C}$ assay in the diagnosis of diabetes. Diabetes Care 2009; 32: 1327-34.

19. Oner RI, Karincaoglu M. Correlation of dyspeptic symptoms and endoscopic findings in diabetic patient. Med Sci Discov 2018; 5: 130-6.

20. Faria M, Pavin EJ, Parisi MCP, Nagasako CK, Mesquita MA. Dyspeptic symptoms in patients with type 1 diabetes: endoscopic findings, Helicobacter pylori infection, and associations with metabolic control, mood disorders and nutritional factors. Arch Endocrinol Metab 2015; 59: 2 .

21. Tseng PH, Lee YC, Chiu HM, et al. Association of diabetes and $\mathrm{HbA1c}$ levels with gastrointestinal manifestations. Diabetes Care 2012; 35: 1053-60.

22. Anastasios R, Goritsas C, Papamihail C, et al. Helicobacter pylori infection in diabetic patients: prevalence and endoscopic findings. Eur J Intern Med 2002; 13: 376-9.

23. Vasihnav BT, Shaikh SR, Bamanikar AA, et al. Diagnostic upper, gastrointestinal endoscopy and prevalence of Helicobacter pylori infection in dispeptic type 2 diabetes mellitus. J Dig Endosc 2018; 9: 53-60. 